\title{
Korelasi Blood Flow Rate Intraoperasi dan Enam Minggu Pascaoperasi Arteriovenous Fistula Brakiosefalika Dihubungkan dengan Maturitas di RSUP Prof. Dr. R. D. Kandou Manado
}

\author{
${ }^{1}$ Aubrey W. Palin, ${ }^{2}$ Djony E. Tjandra, ${ }^{2}$ Richard M. Sumangkut \\ ${ }^{1}$ PPDS Ilmu Bedah Fakultas Kedokteran Universitas Sam Ratulangi Manado \\ ${ }^{2}$ Divisi Bedah Vaskular Bagian Ilmu Bedah Universitas Sam Ratulangi/RSUP Prof. Dr. R. \\ D. Kandou Manado \\ Email: aubreypalin@gmail.com
}

\begin{abstract}
American National Kidney Foundation (2002) states that end-stage kidney disease is an indication for renal replacement therapy, one of which is hemodialysis. Vascular access comprises a fundamental component of hemodialysis therapy (HD), facilitating the patient's blood flow to the dialyzer. However, there are some factors affecting the maturity of an arteriovenous fistula (AVF), inter alia the patient, comorbidities, and anatomical and functional conditions of the blood vessels involving the blood flow rate (BFR). This study was aimed to establish the differences between intra-operative BFR and BFR six weeks after surgery as well as any correlations between intraoperative BFR, venous diameter, and skin to vein distance with maturity of brachiocephalic AVF. This was prospective cohort study conducted at the Department of Surgery, Prof. Dr. R. D. Kandou General Hospital Manado. Subjects were 41 CKD patients who underwent brachiocephalic AVF surgery. The vein diameter, skin to vein distance, and BFR were measured immediately as intra-operative data using a Doppler USG and all were re-measured at six-week-follow-up examination as six-week-postoperative data. The results showed that there was a significant increase in BFR at six weeks postoperation compared to intraoperation $(\mathrm{t}=-19.215 ; P<0.0001)$. Biserial point correlation analysis revealed that there was a significant correlation between intraoperative venous diameter and maturity $(\mathrm{rpb}=0.276 ; P=0.04)$ as well as a significant correlation between intraoperative BFR and maturity $(\mathrm{rpb}=0.615 ; P=0.002)$. No significant correlation was observed between intra-operative skin to vein distance and maturity $(\mathrm{rpb}=0.093$; $P=0.281$ ). Conclusion: There was a significant difference in BFR between intraoperation and 6 weeks postoperation in the mature $\mathrm{AV}$ fistula. There was a significant relationship between intraoperative BFR and maturity as well as between intraoperative venous diameter and maturity, while no significant relationship between skin-vein distance and maturity was found.
\end{abstract}

Keywords: brachiocephalic AVF, BFR, maturity

\begin{abstract}
Abstrak: American National Kidney Foundation (2002) menyatakan bahwa penderita dengan penyakit ginjal tahap akhir diindikasikan untuk dilakukan terapi pengganti ginjal, salah satunya hemodialisis (HD). Akses vaskular merupakan komponen penting pada terapi HD karena melalui akses vaskular darah dari tubuh pasien dapat dialirkan menuju dialyzer. Terdapat banyak faktor yang memengaruhi maturitas suatu arteriovenous fistula (AVF), yaitu pasien itu sendiri, komorbid, serta keadaan anatomi dan fungsional pembuluh darah termasuk nilai blood flow rate (BFR). Penelitian ini bertujuan untuk mengetahui perbedaan BFR intraoperasi dan BFR enam minggu pascaoperasi serta adanya korelasi antara BFR intraoperasi, diameter vena, dan jarak kulit-vena dengan maturitas AVF brakiosefalika. Penelitian ini dilaksanakan di Bagian Bedah RSUP Prof. Dr. R. D. Kandou Manado dengan desain kohort prospektif. Subyek penelitian ialah 41 pasien PGK yang menjalani operasi pembuatan AVF brakiosefalika. Setelah selesai operasi dihitung diameter vena, jarak kulit-vena, dan BFR sebagai data intraoperasi menggunakan USG Doppler. Penghitungan dilakukan kembali 6 miggu pascaoperasi. Hasil penelitian mendapatkan peningkatan BFR yang sangat bermakna pada enam minggu pascaoperasi dibandingkan intraoperasi $(t=-$ $19,215, P<0,0001)$. Dengan analisis korelasi point biserial didapatkan hubungan bermakna antara diameter vena intraoperasi dengan maturitas $\left(\mathrm{r}_{\mathrm{pb}}=0,276 ; P=0,04\right)$, tidak terdapat hubungan
\end{abstract}


bermakna antara jarak kulit-vena intraoperasi dengan maturitas $\left(\mathrm{r}_{\mathrm{pb}}=0,093 ; P=0,281\right)$, dan terdapat hubungan bermakna antara BFR intraoperasi dengan maturitas $\left(\mathrm{r}_{\mathrm{pb}}=0,615 ; P=0,002\right)$. Simpulan: Terdapat perbedaan bermakna antara BFR intraoperasi dan BFR 6 minggu pascaoperasi pada AVF matur. Terdapat hubungan bermakna antara BFR intraoperasi dan diameter vena intraoperasi dengan maturitas namun tidak terdapat hubungan bermakna antara jarak kulit-vena dengan maturitas.

Kata kunci: AVF brakiosefalika, BFR, maturitas

Penyakit ginjal kronik (PGK) atau chronic kidney disease (CKD) merupakan penyakit yang masih menjadi momok bagi masyarakat Indonesia. Angka kejadian menunjukkan tren yang meningkat dari tahun ke tahun. PGK ditandai dengan nilai glomerular filtration rate (GFR) kurang dari 60 $\mathrm{mL} / \mathrm{menit} / 1,73 \mathrm{~m}^{2}$ yang terjadi selama lebih dari 3 bulan. ${ }^{1,2}$ Penyebab utama penyakit ini ialah diabetes melitus (DM) dan hipertensi. American National Kidney Foundation (2002) menyatakan bahwa penderita dengan penyakit ginjal tahap akhir diindikasikan untuk dilakukan renal replacement therapy (RRT) atau terapi pengganti ginjal. Tujuan terapi ini untuk meningkatkan kualitas hidup pasien yang menderita penyakit ginjal tahap akhir. ${ }^{3}$ Terdapat dua jenis terapi pengganti ginjal, yaitu dialisis dan transplantasi. Dialisis sendiri terbagi atas hemodialisis (HD) dan peritoneal dialisis (PD). Jenis HD lebih banyak dipilih karena proses yang lebih singkat dan lebih efisien terhadap pengeluaran zat-zat dengan berat molekul rendah, ${ }^{4}$ walaupun pilihan ini mengharuskan penderita untuk datang ke runah sakit atau sarana kesehatan lainnya yang menyediakan mesin hemodialisa.

Akses vaskular merupakan komponen penting pada terapi HD karena melalui akses vaskular darah dari tubuh pasien dapat dialirkan menuju dialyzer. ${ }^{5}$ Terdapat dua kategori tempat akses vaskular yaitu perkutaneus (jugularis, subklavia dan femoralis) dan arteriovenous/AV (fistula/native dan graft). Akses AV fistula (AVF) dan graft merupakan akses permanen yang dibuat melalui pembedahan pada lengan kiri bagian bawah. Pada AVF, pembedahan dilakukan untuk membuat anastomosis antara pembuluh darah arteri dan vena. Proses pematangan anastomosis tersebut membutuhkan waktu antara 6-12 minggu karena dalam waktu tersebut segmen fistula dapat berdilatasi dengan baik. ${ }^{5}$

Dialisis dikatakan adekuat bila aliran darah ekstrakorporeal mencapai 350 $\mathrm{mL} / \mathrm{menit}$. Hal ini dimungkinkan bila aliran darah pada akses vaskular hemodialisis juga mencapai $450-500 \mathrm{~mL} /$ menit. Akses vaskular yang diketahui paling mendekati ideal ialah dengan $\mathrm{AVF}^{6}{ }^{6}$ namun banyak faktor yang memengaruhi maturitas suatu AVF, selain faktor dari pasien itu sendiri termasuk penyakit penyerta (komorbid) maupun keadaan anatomi dan fungsional dari pembuluh darah termasuk nilai blood flow rate (BFR) yang dimilki. Setelah diberikan waktu untuk pematangan, BFR diteliti apakah berpengaruh pada maturasi suatu AVF.

\section{METODE PENELITIAN}

Penelitian ini dilakukan dengan desain kohort prospektif untuk mendapatkan perbandingan BFR intraoperasi dengan BFR 6 minggu pascaoperasi serta hubungannya dengan maturasi klinis AVF pada penderita yang menjalani hemodialisis. Penelitian berlangsung selama 6 bulan (Oktober 2018-Maret 2019) di Bagian Bedah RSUP Prof. Dr. R. D. Kandou dan telah mendapatkan persetujuan dari Komisi Etik Penelitian Kesehatan RSUP Prof. Dr. R. D. Kandou Manado. Pasien bersedia untuk berpartisipasi dalam penelitian dengan menandatangani surat persetujuan (informed consent) setelah mendapat keterangan tentang keuntungan dan risiko yang dapat terjadi selama penelitian.

Kriteria inklusi ialah pasien PGK stadium 5 yang akan menjalani operasi pembuatan arteriovenous fistula brakiosefalika di Divisi Vaskular dan Endovaskular FK Universitas Sam Ratulangi - 
RSUP Prof. Dr. R. D. Kandou Manado dan setuju untuk ikut dalam penelitian ini. Kriteria eksklusi ialah pasien sudah dilakukan kanulasi sebelum 6 minggu, terdapat stenosis vena sentral, sementara terpasang kateter double lumen pada sisi yang sama dengan lokasi pembuatan AVF, dilakukan AVF brakiobasilika, dan pasien tidak datang kontrol.

Pasien yang direncanakan untuk dilakukan AVF, dilakukan pemeriksaan sesuai standar operasional Divisi Vaskular Fakultas Kedokteran Universitas Sam Ratulangi - RSUP Prof. Dr. R. D. Kandou Manado. Sebelum dilakukan operasi, dicatat karakteristik pasien (usia, jenis kelamin, komorbid) dan dilakukan pemeriksaan fisik dan mapping pembuluh darah. Pada pasien yang memenuhi kriteria inklusi dilakukan pembuatan AVF brakiosefalika oleh dokter spesialis bedah vaskuler dan segera setelah selesai operasi dihitung diameter vena, jarak kulit-vena, dan BFR sebagai data intraoperasi menggunakan alat ultrasonografi (USG) Doppler. Enam minggu kemudian pasien kontrol kembali dan dihitung kembali diameter vena, jarak kulit-vena, dan BFR sebagai data enam minggu pascaoperasi.

Data awal dilakukan analisis deskriptif untuk mendapatkan karakteristik subjek penelitian, kemudian dibandingkan antara BFR intraoperasi dan BFR 6 minggu pascaoperasi AVF baik yang matur (matur fungsional) maupun yang tidak matur. Uji statistik yang digunakan ialah uji $t$ berpa- sangan dan analisis korelasi point biserial.

\section{HASIL PENELITIAN}

Sebanyak 47 pasien PGK turut berpartisipasi dalam penelitian ini, namun hanya 41 pasien yang dimasukkan dalam penelitian karena 6 pasien lainnya tidak datang kontrol dalam waktu yang ditentukan.

Hasil yang didapat menunjukkan sebaran jenis kelamin lebih banyak pada laki-laki $(75,6 \%)$ dibandingkan perempuan $(24,4 \%)$. Komorbid yang menyertai ialah DM sebanyak 16 pasien $(39,0 \%)$, hipertensi sebanyak 23 pasien $(56,1 \%)$ dan hiperurisemia sebanyak 25 pasien $(61,0 \%)$. Untuk temuan intraoperasi, rerata diameter vena yang didapat sebesar $3,86 \mathrm{~mm}$, rerata jarak vena dari kulit $3,10 \mathrm{~mm}$, dan rerata BFR ialah 187,78 ml/menit. Dari 41 pasien yang dibuatkan AV fistula brakiosefalika ini didapat 4 pasien $(9,76 \%)$ mengalami kegagalan maturasi fungsional dan 37 $(90,24 \%)$ pasien mengalami maturasi fungsional (Tabel 1). Pada 6 minggu pascaoperasi, pasien kontrol kembali dan dievaluasi kembali diameter vena, jarak kulit vena, dan BFR (Tabel 2).

Perbedaan diameter vena intraoperasi dan sesudah 6 minggu diuji dengan uji $t$ berpasangan, yang menyatakan terdapat peningkatan diameter vena secara sangat bermakna setelah 6 minggu pascaoperasi $(P<0,0001)$. Sebaran data diameter vena intraoperasi dan 6 minggu pascaoperasi ditampilkan dalam grafik (Gambar 1).

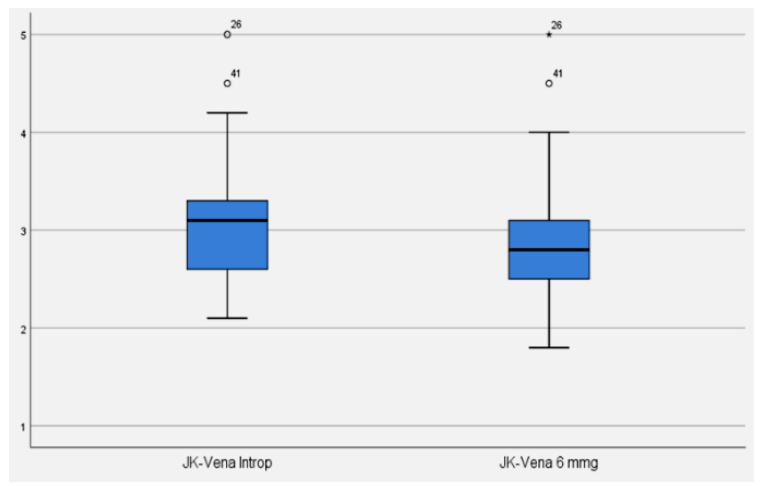

Gambar 2. Sebaran data jarak kulit-vena intraoperasi dan 6 minggu pasca operasi
Gambar 1. Sebaran data diameter vena intraoperasi dan 6 minggu pascaoperasi

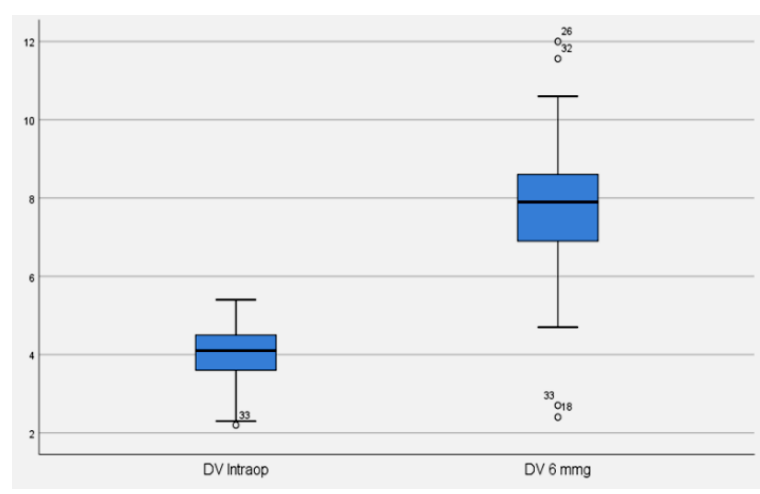


126 Jurnal Biomedik (JBM), Volume 11, Nomor 2, Juli 2019, hlm. 123-130

Tabel 1. Distribusi karakteristik pasien dalam penelitian

\begin{tabular}{lccc}
\hline \multicolumn{1}{c}{ Karakteristik } & Frekuensi & Persentase & Mean \pm SD \\
\hline Usia (tahun) & & & $56,32 \pm 11,114$ \\
Jenis kelamin & 31 & 75,6 & \\
Laki-laki & 10 & 24,4 & \\
Perempuan & 41 & 100 & \\
$\quad$ Total & & & \\
Diabetes melitus & 25 & 61,0 & \\
Tidak ada DM & 16 & 39,0 & \\
Ada DM & 41 & 100 & \\
Total & & & \\
Hipertensi & 18 & 43,9 & \\
Tidak hipertensi & 23 & 56,1 & \\
Ada hipertensi & 41 & 100 & \\
Total & & & \\
Hiperurisemia & 16 & 39,0 & \\
Tidak ada hiperurisemia & 25 & 61,0 & \\
Ada hiperurisemia & 41 & 100 & \\
Total & & & $3,8610 \pm 0,85612$ \\
Data intraoperasi & & & \\
Diameter vena (mm) & & & \\
Jarak kulit-vena (mm) & & & \\
BFR (ml/m) & & & \\
Maturitas & & & \\
Tidak matur & 4 & & \\
Matur & 41 & & \\
Total & & & \\
\hline
\end{tabular}

Tabel 2. Perbedaan intraoperasi dan 6 miggu pascaoperasi

\begin{tabular}{lcccccc}
\hline & \multicolumn{2}{c}{ Diameter vena } & \multicolumn{2}{c}{ Jarak kulit-vena } & \multicolumn{2}{c}{ BFR } \\
\hline & Intraop & 6 minggu & Intraop & 6 minggu & Intraop & 6 minggu \\
$\mathrm{N}$ & 41 & 41 & 41 & 41 & 41 & 41 \\
Minimum & 2,20 & 2,40 & 2,10 & 1,80 & 120,42 & 15,03 \\
Maksimum & 5,40 & 12,00 & 5,00 & 5,00 & 254,83 & 698,76 \\
Mean & 3,8610 & 7,7600 & 3,1049 & 2,8805 & 187,7800 & 541,5495 \\
SD & 0,85612 & 1,96273 & 0,64185 & 0,70930 & 26,71455 & 155,23618 \\
Uji t & $-14,423(P<0,0001)$ & $7,863(P<0,0001)$ & $-19,215(P<0,0001)$ \\
\hline
\end{tabular}

Ket: intraop, intraoperasi

Perbedaan jarak kulit-vena intraoperasi dan 6 minggu pascaoperasi diuji dengan uji $\mathrm{t}$ berpasangan, yang menyatakan terdapat penurunan diameter vena secara sangat bermakna pada 6 minggu pascaoperasi $(P<$ 0,0001). Sebaran data jarak kulit-vena intraoperasi dan 6 minggu pascaoperasi ditampilkan dalam grafik (Gambar 2).

Perbedaan BFR intraoperasi dan 6 minggu pascaoperasi diuji dengan uji $\mathrm{t}$ berpasangan, yang menyatakan terdapat peningkatan BFR secara sangat bermakna 
pada 6 minggu pascaoperasi $(P<0,0001)$. Sebaran data BFR intraoperasi dan 6 minggu pascaoperasi ditampilkan dalam grafik (Gambar 3).

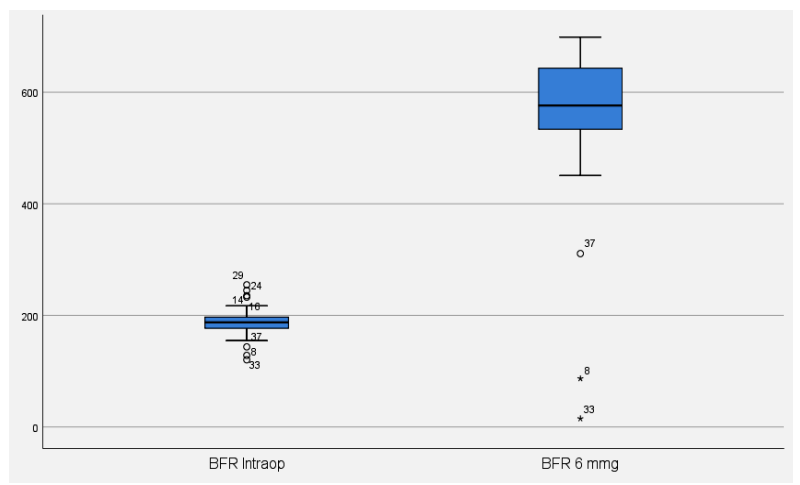

Gambar 3. Sebaran Data BFR Intraoperasi dan 6 minggu
Hubungan antara diameter vena intraoperasi, jarak kulit-vena intraoperasi, dan BFR intraoperasi dengan maturitas diuji dengan analisis korelasi point biserial, sebab variabel marturitas hanya terdiri atas dua kategori (matur dan tidak matur). Hasil analisis memperlihatkan adanya hubungan bermakna antara diameter vena intraoperasi dengan maturitas $\left(\mathrm{r}_{\mathrm{pb}}=0,276\right.$ dengan nilai $P=0,04<0,05)$; tidak terdapat hubungan bermakna antara jarak kulit-vena intraoperasi dengan maturitas $\left(\mathrm{r}_{\mathrm{pb}}=0,093\right.$ dengan nilai $P=0,281>0,05)$; dan terdapat hubungan bermakna antara BFR intraoperasi dengan maturitas $\left(\mathrm{r}_{\mathrm{pb}}=0,615\right.$ dengan nilai $P=0,002<0,05)($ Tabel 3).

Tabel 3. Hubungan diameter vena inreaoperasi, jarak kulit-vena intraoperasi, dan BFR dengan maturitas

\begin{tabular}{clccc}
\hline \multirow{2}{*}{ Maturitas } & $\begin{array}{c}\text { Diameter vena } \\
\text { intraoperasi }\end{array}$ & $\begin{array}{c}\text { Jarak kulit-vena } \\
\text { intraoperasi }\end{array}$ & $\begin{array}{c}\text { BFR } \\
\text { intraoperasi }\end{array}$ \\
\cline { 2 - 5 } & Point biserial correlation & 0,276 & 0,093 & 0,615 \\
& Sig. (1 tailed) & 0,040 & 0,282 & 0,000 \\
N & 41 & 41 & 41 \\
\hline
\end{tabular}

\section{BAHASAN}

Pada penelitian ini dinilai karakteristik subyek penelitian berupa usia, jenis kelamin, dan komorbid yang ada. Selain itu juga dinilai temuan intraoperasi berupa diameter vena, jarak vena ke kulit, dan blood flow rate draining vein, kemudian dihubungkan dengan maturitas. Dari 41 pasien yang dibuatkan AVF brakiosefalika, diperoleh 4 pasien $(9,76 \%)$ yang mengalami kegagalan maturasi fungsional dan $37(90,24 \%)$ pasien mengalami maturasi fungsional.

Secara karakteristik, rerata usia pasien yang menjalani pembuatan AVF brakiosefalika di RSUP Prof. Dr. R. D. Kandou dari Oktober 2018 s/d Maret 2019 ialah $56,3 \pm 11,1$ tahun. Hal ini tidak jauh berbeda dengan penelitian oleh Pratama et al $^{7}$ yang melaporkan rerata usia 48,8 tahun dengan standar deviasi 11,24 tahun. Bila dihubungkan dengan maturitas, pada penelitian ini dinyatakan tidak terdapat perbedaan bermakna rerata usia pada AVF brakiosefalika yang matur dan yang tidak matur $(P=0,817)$. Hal ini selaras dengan laporan oleh Zhu et $\mathrm{al}^{8}$ yang melaporkan tidak terdapat perbedaan bermakna pada usia pasien. Berbeda dengan yang dilaporkan oleh Woodside et $\mathrm{al}^{9}$ yaitu kelompok usia muda ( $\leq 44$ tahun) memiliki angka keberhasilan menjadi AVF matur yang tinggi dan lebih singkat dibandingkan kelompok usia yang lebih tua.

Pada penelitian ini didapatkan jumlah subyek berjenis kelamin laki-laki lebih banyak dibandingkan perempuan $(75,6 \%$ vs $24,4 \%$ ). Hasil ini sesuai dengan penelitian Zhu et al ${ }^{8}$ yang mendapatkan pasien berjenis kelamin laki-laki lebih banyak dibandingkan perempuan $(56,3 \%$ vs $43,7 \%)$. Demikian pula dengan penelitian yang dilakukan oleh Pratama et $\mathrm{al}^{7}$ yang mendapatkan laki-laki : perempuan $=52,3: 47,7$. 
Bila dihubungkan dengan maturitas, didapatkan tidak terdapat perbedaan bermakna dalam sebaran jenis kelamin pada AVF yang matur dan yang tidak matur $(P=0,689)$. Hal ini selaras dengan yang dilaporkan oleh Pratama et al $^{7}$ yaitu tidak terdapat perbedaan bermakna dalam hal jenis kelamin untuk AVF brakiosefalika yang matur dan yang tidak matur. Berbeda dengan yang dilaporkan oleh Woodside et $\mathrm{al}^{9}$ yaitu pada observasi di Amerika didapatkan AVF laki-laki lebih cepat dan lebih besar kemungkinan menjadi matur dibandingkan perempuan. Sama halnya dengan yang dilaporkan oleh Hal tersebut sesuai dengan laporan Siddiqui et $\mathrm{al}^{10} \mathrm{di}$ Kanada yang mendapatkan angka kejadian maturasi AVF pada laki-laki 2 kali lebih besar dibandingkan perempuan.

Pada penelitian ini, dinilai DM, hipertensi, dan hiperurisemia sebagai komorbid yang menyertai. Komorbid DM didapatkan sebanyak 16 pasien $(39 \%)$ yang menyandang DM menjalani pembuatan AVF dan 25 pasien $(61 \%)$ tidak menyandang DM. Hal ini sejalan dengan yang dilaporkan oleh Zhu et al $^{8}$ yang mendapatkan sebanyak $24,3 \%$ pasien yang menyandang DM sebagai primary renal disese. Bila dihubungkan dengan maturitas, terdapat sebanyak $3(75 \%)$ dari 4 pasien yang tidak matur, namun tidak terdapat perbedaan bermakna antara sebaran pada yang menyandang DM dengan angka kejadian matur suatu AVF brakiosefalika $(P=$ 0,156). Hal ini selaras dengan yang dilaporkan oleh Murphy ${ }^{11}$ yaitu tidak terdapat perbedaan bermakna dalam angka kejadian matur dari elbow AVF dengan yang matur dihubungkan dengan kelompok non-diabetik dan kelompok diabetik.

Pada penelitian ini didapatkan sebanyak 23 pasien $(56,1 \%)$ dengan komorbid hipertensi dan AVF yang dibuat semuanya menjadi matur, sedangkan dari 18 pasien $(43,9 \%)$ yang tidak menyandang hipertensi terdapat 14 pasien yang tetap matur dan 4 pasien lainnya tidak matur. Bila dihubungkan dengan maturitas AVF, terdapat perbedaan bermakna sebaran hipertensi pada kejadian matur suatu AVF brakio- sefalika dan yang tidak matur $(P=0,030)$. Hal ini sesuai dengan penelitian Woodside et $\mathrm{al}^{9}$ yang mendapatkan penyandang hipertensi memiliki hubungan dengan angka keberhasilan yang tinggi suatu AVF menjadi matur. Hal ini berbeda dengan acuan pustaka lainnya yang menyatakan bahwa faktor risiko seperti penyakit kardiovaskular, hiperlipidemia, dan hipertensi dapat menurunkan kemungkinan menjadi maturnya suatu AVF, dengan asumsi terjadinya disfungsi endotel pada penyandang hipertensi. ${ }^{12}$

Hiperurisemia merupakan salah satu komorbid yang diamati pada penelitian ini mengingat cukup tinggi jumlah pasien PGK dengan komorbid ini Hal ini sesuai dengan acuan pustaka yang menyatakan bahwa hiperurisemia mempunyai hubungan erat dangan angka kejadian PGK tahap akhir. ${ }^{13}$ Pada penelitian ini didapatkan 25 pasien (61\%) yang menyandang hiperurisemia, dan terdapat 23 pasien dengan AVF yang menjadi matur, dan hanya 2 pasien dengan AVF yang tidak matur. Terdapat 16 subyek $(39 \%)$ yang tidak menyandang hiperurisemia; 14 pasien dengan AVF yang menjadi matur dan pada 2 pasien tidak matur. Hal ini menunjukkan tidak terdapat perbedaan bermakna dari sebaran data hiperurisemia pada kejadian matur dan tidak matur.

Untuk temuan intraoperasi, rerata diameter vena yang didapat $3,86 \pm 0,85 \mathrm{~mm}$. Pada 6 minggu pascaoperasi terjadi peningkatan rerata ukuran diameter vena yaitu 7,76+1,96 mm. Hal ini menunjukkan adanya peningkatan yang sangat bermakna $(P<0,0001)$. Bila dihubungkan dengan maturitas, diperoleh adanya perbedaan bermakna ukuran diameter vena intraoperasi terhadap maturitas $\left(\begin{array}{lll}P & 0,04<0,05\end{array}\right)$. Smith et $\mathrm{al}^{14}$ menyatakan angka keberhasilan menjadi matur lebih tinggi pada ukuran vena yang besar yaitu kemungkinan menjadi matur secara bermakna meningkat untuk vena sefalika dengan diameter $>2,0 \mathrm{~mm}$. Hal ini sesuai dengan hasil penelitian ini yaitu semua AVF yang matur memiliki diameter vena intraoperasi $>2,0 \mathrm{~mm}$ (minimum 2,3 mm, dan maksimum 5,4 mm). 
KDOQI menganjurkan ke dalam vena $<6 \mathrm{~mm}$ yang akan dipakai untuk pembuatan AVF. ${ }^{15}$ Rerata jarak vena dari kulit $3,10+0,64 \mathrm{~mm}$ pada intraoperasi, namun setelah 6 minggu didapatkan penurunan rerata yang sangat bermakna yaitu 2,88 $+0,70 \mathrm{~mm}$, sedangkan pada AVF yang matur terdapat penurunan dari rerata 3,12 $\mathrm{mm}$ menjadi $2,87 \mathrm{~mm}$, yang menunjukkan pada 6 minggu pascaoperasi jarak vena makin dekat dengan kulit. Walaupun begitu, setelah dihubungkan dengan maturitas, untuk jarak kulit-vena intraoperasi tidak didapatkan adanya hubungan bermakna dengan maturitas $(P=0,281>0,05)$. Hal ini selaras dengan yang dilaporkan Farrington et $\mathrm{al}^{16}$ yaitu terdapat penurunan jarak kulit-vena terutama pada kelompok yang matur, namun nilainya tidak bermakna.

Rerata BFR yang didapat intraoperasi oalah $187,78+26,7 \mathrm{ml} / \mathrm{menit}$, dan pada 6 minggu pascaoperasi didapatkan peningkatan rerata BFR secara sangat bermakna yaitu 541,54+155,23 $\mathrm{ml} / \mathrm{menit}$. Hasil ini sejalan dengan yang dilaporkan Pratama et $\mathrm{al}^{7}$ yang mendapatkan rerata BFR intraoperasi 262,5 $\mathrm{ml} / \mathrm{menit}$ dan rerata BFR setelah 6 minggu sebesar $508 \mathrm{ml} /$ menit. Bila dihubungkan dengan maturitas, terdapat hubungan bermakna antara BFR intraoperasi dengan maturitas $(P=0,002<0,05)$. Laporan Pratama et $\mathrm{al}^{7}$ dan Zhu et $\mathrm{al}^{17}$ menyatakan bahwa terdapat peningkatan BFR yang bermakna pada AVF brakiosefalika yang menjadi matur.

Pada penelitian ini tidak didapatkan $c u t$ off point dari nilai BFR intraoperasi yang diprediksi dapat menjadi matur oleh karena hasil analisis dengan kurva ROC, diperoleh area under the curve (AUC) $=1$, sehingga analisis ROC tidak layak digunakan. Namun penelitian di China melaporkan bahwa cut off point BFR untuk AVF brakiosefalika yang didapat sebesar 529 $\mathrm{ml} / \mathrm{menit}$ dan di Jakarta sebesar 245,5 $\mathrm{ml} / \mathrm{menit}^{7,17}$

\section{SIMPULAN}

Terdapat perubahan bermakna dalam diameter vena dan jarak kulit-vena antara intraoperasi dan 6 minggu pascaoperasi. Terdapat hubungan bermakna antara BFR intra-operasi dan diameter vena dengan maturitas, namun tidak terdapat hubungan bermakna antara jarak kulit-vena dengan maturitas AVF.

\section{DAFTAR PUSTAKA}

1. Myers D, Myers S. Systemic complications: renal. In: Cronenwett JL, Johnston KW, editors. Rutherford's Vascular Surgery (8th ed). Philadelphia: Saunders Elsevier, 2014.

2. Kallenbach JZ, Gutch CF, Stoner MH, Corca AL. Hemodialysis for Nurses and Dialisis Personal (7th ed). St Louis Missouri: Saunders Elsevier, 2005.

3. Thomas N. Renal Nursing (2nd ed). London: Elsevier Science, 2002.

4. Ignatavicius DD, Workman ML. Medical Surgical Nursing: Critical Thinking for Collaborative Care (5th ed). St Louis Missouri: Elsevier Saunders, 2006.

5. Sudoyo AW, Sutiyahadi B, Alwi I, Simadibrata M, Setiati S. Buku Ajar Ilnu Penyakit Dalam, Jilid II (4th ed). Jakarta: Pusat Penerbitan Departemen Ilmu Penyakit Dalam Fakultas Kedokteran Universitas Indonesia, 2006.

6. Berman S, Mendoza B, Westerband A. Predicting arteriovenous fistula maturation with intraoperative blood flow measurements. J Vasc Access. 2008 9:241-7.

7. Pratama Danny, Pratama D, Kekalih A. Blood flow rate intraoperatif sebagai prediktor maturitas fistula arteriovenous brakiosefalika. J Ilmu Bedah Indonesia. 2014;43(2):120-7.

8. Zhu YL, Ding H, Fan PL, Gu QL, Teng J, Wang WP. Is brachial artery blood flow measured by sonography during early postoperative periods predictive of arteriovenous fistula failure in haemodialysis patients? J Ultrasound Med. 2016;35:1985-92.

9. Woodside KJ, Bell S, Mukhopadhyay P, Repeck KJ, Robinson IT, Eckard $\mathbf{A R}$, et al. Arteriovenous fistula maturation in prevalent hemodialysis patients in the united states: a national study. Am J Kidney Dis. 2018;71(6): 793-801. 
10. Siddiqui MA, Ashraff S, Santos D, Rush R, Carline T, Raza Z, et al. Predictive parameters of arteriovenous fistula maturation in patients with end-stage renal disease. Kidney Res Clin Pract 2018; 37:277-286.

11. Murphy GJ, Nicholson ML. Autogeneous elbow fistulas: the effect of diabetes mellitus on maturation, patency, and complication rates. Eur $\mathrm{J}$ Vasc Endovasc Surg. 2002;23:452-7.

12. Siddiqui MA, Ashraff S, Carline T. Maturation of arteriovenous fistula: analysis of key factors. Kidney Res Clin Pract. 2017;36:318-28.

13. Vargas-Santos AB, Neogi T. Management of gout and hyperuricemia in CKD. Am J Kidney Dis. 2017;70(3):422-39.

14. Konner K, Hulbert-Shearon TE, Roys EC, Posrt FK. Tailoring the initial vascular for dialysis patients. Kidney Int. 2002; 62:329-38.

15. K/DOQI 2006 Updates clinical practice guidelines and recommendations. National Kidney Foundation. 2006, 2. Available from: http://www.kidney.org/ Professionals/kdoqi.

16. Farrington CA, Robbin ML, Lee T, Barker-Finkel J, Allon M. Postoperative ultrasound, unassisted maturation, and subsequent primary patency of arteriovenous fistulas. Clin J Am Soc Nephrol. 2018;13(9):1364-72.

17. Zhu YL, Ding H, Fan PL, Gu QL, Teng J, Wang WP. Predicting the marturity of haemodialysis arteriovenous fistulas with colour Doppler ultrasound: a single centre study from China. Clin Radiol. 2016;71:576-82. 